\title{
Basic Module of Health Promotion
}

\section{Uqbah Iqbal}

Faculty of Social Sciences and Humanities, UKM, Bangi Selangor, Malaysia

Corresponding author: Uqbah Iqbal, Faculty of Social Sciences and Humanities, UKM 43650, Bangi Selangor, Malaysia, Tel: 60389215555; Email: uqbah@siswa.ukm.edu.my

Received: 15 January 2017; Accepted: 20 January 2017; Published: 24 January 2017

Citation: Iqbah U. Basic Module of Health Promotion. Ann Clin Lab Res. 2017, 5: 1.

\section{Opinion}

This module provides a guide for organizations to implement health promotion among society. There are four units in this module, namely the Health Promotion, Program Planning, Communications, and Program Evaluation. The module is expected to bring benefits to all organizations that carry out health promotion projects not only in Malaysia but throughout the world. Congratulations to all specialist involved in the drafting of the Basic module of Health Promotion for producing content that should be known by the organizations involved in health promotion activities. This module is expected to be a guide and a starting point in the realization of MySihat dream to empower organizations through capacity building process. MySihat (Malaysian Health Promotion Board) has been operating on 1 April 2007 following the proclamation of the Malaysian Health Promotion Board Act 2006 (Act 651). MySihat main objective is to expand the field of health promotion and community involvement intensively driven together through non-governmental organizations (NGOs).

Its mission is for the Malaysians to become healthy and active. Its vision is to become a center of excellence at national and international level in the field of health promotion through lifestyle, environment, and public health. MySihat core service is to build the organization's efforts in the field of training and health promotion through grants or other financial assistance to help programs and health promotion activities. Fields of health promotion priority for any application is the control and prevention of tobacco use and alcohol, promotion and healthy lifestyles such as the promotion of exercise or physical activity and healthy eating, environmental health, mental health, cancer prevention, diabetes prevention, disease prevention cardiovascular, prevention of obesity (overweight), sexual health (including HIV/AIDS), research in the field of health promotion and health promotion through sports activities and cultural.

This module is produced for the purpose of training nongovernmental organization (NGO) and as guide to the NGO intends to implement health program promotion. NGOs need to have knowledge about health promotion aspects in planning, implementing and evaluating the activities that are carried out. This module contains four modules, namely the health promotion unit, program planning, communications, and program evaluation. Each unit consists of introduction, learning objectives, content, learning activities, teaching tools and assessment. The objective of the training is to build organizations that seek elected as a facilitator in the field of health promotion, prevention of obesity and eating healthy. Learning plan should be prepared in accordance with the guidance provided in the module. Each session shall be documented by title, objectives, methodology, equipment, venue, date, budget, guest speakers, training evaluation, training effectiveness evaluation (pre and post assessment) and conclusion.

Health Promotion module is a guide to organizations who wish to implement program health promotion. Organizations need to have knowledge of health promotion about aspect in planning, implementing and evaluating promotion activities conducted. Subject health should be simplified with the use and application of academic theories and models that can be kept to a minimum, just to strengthen argument only than it should be simple and practical. Conceptually, Percel et al. in 1981, states that health promotion is an efforts to build health-related knowledge, skills and attitudes through the use of behavioral theory. Ajzen et al. in 1980 stated the theory that the cause of the behavior humans will behave according to their attitudes and beliefs about the benefits or costs resulting from behavior practiced. In addition, he also discusses the individual perception related to social pressures that influence individuals to change their behavior.

Simonds in 1976, also noted that health promotion seeks to bring behavior change for individuals, groups and the whole population from current behavior to the nice behavior for health, current problematic behavior to the future health behavior. Minkler in 1989, stated briefly that health promotion and health education is a combination of health education and health advocacy. In setting the direction of a health promotion program among health promotion body and public health authorities around the world, a health promotion strategy has been developed which is designated as the Ottawa Charter for Health Promotion. This charter has been accepted and agreed in First International Conference on Health Promotion held on 21 November 1986 in Ottawa, Canada. It is an expression of the vision of the international community towards achieving 'Health for All' for the decade of 2000 and beyond. Health promotion is beyond the scope of health care only. Health should be on the agenda of policy makers in every sector and level; to ensure they are aware of the implications and responsible for the consequences of decisions or policies formulated for the health. 
